\title{
Comparison study between seven-level SVPWM and two-level SVPWM strategy in direct vector control of a DFIG-based wind energy conversion systems
}

Habib Benbouhenni

Department of Electrical Engineering, National Polytechnique School of Oran Maurice Audin, Algeria

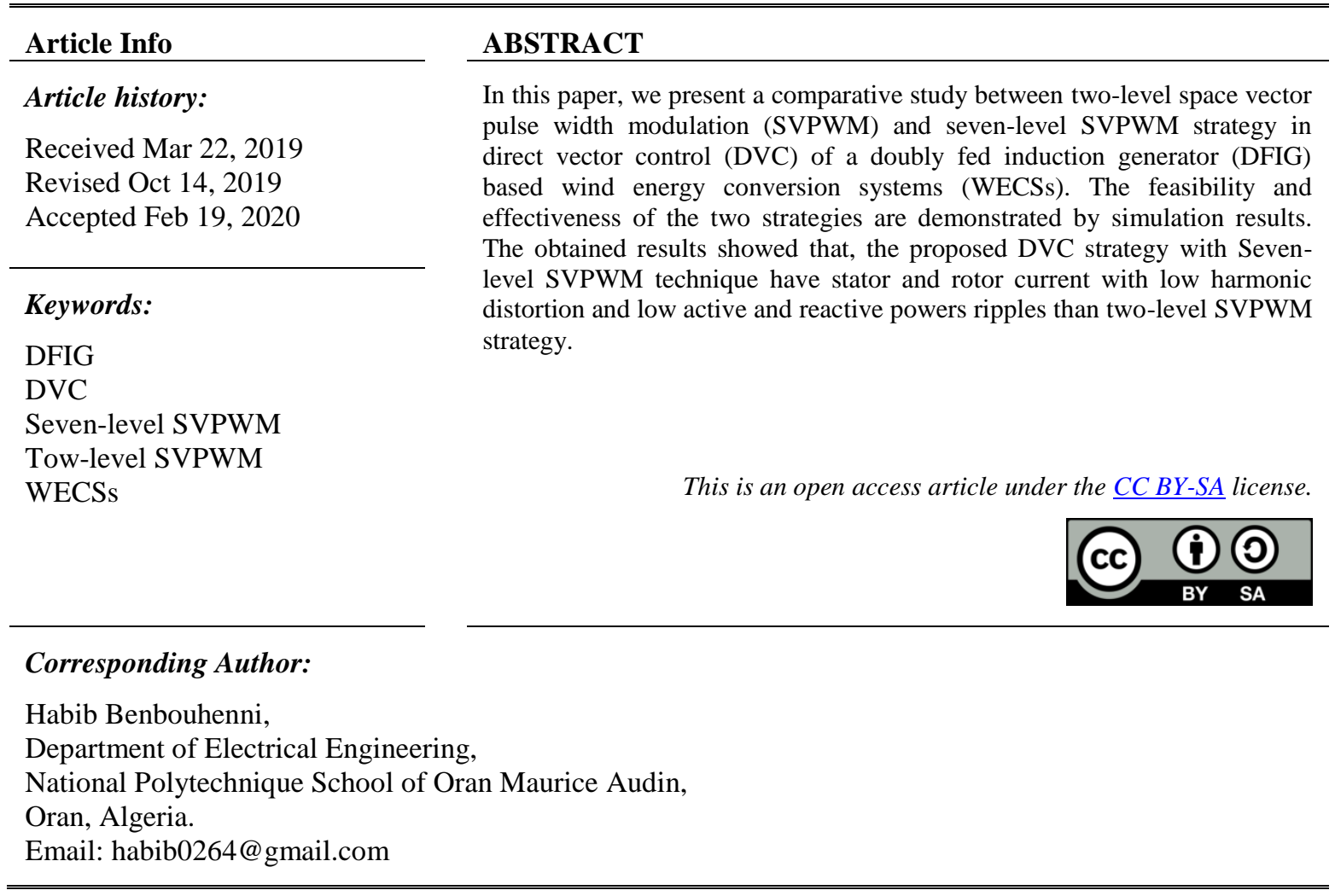

\section{INTRODUCTION}

Traditionally, direct vector control (DVC) strategy with proportional-integral (PI) regulators is the usual strategy employed currently for wind energy conversion systems (WECSs) based on doubly fed induction generator (DFIG) [1]. This strategy presents a good decoupling between the two currents axes $(d$ and $q$ ), therefore the model of the DFIG becomes simple and PI regulators can be employed. However, this strategy of control is highly depending on the accuracy of the machine parameters, employs divers loops and needs a big regulation strength in order to ensures stability during the whole speed domain [2].

In multilevel inverter, many strategies such as selective harmonic elimination (SHE) [3], pulse width modulation (PWM) [4], space vector pulse width modulation (SVPWM) strategy [5], and active harmonic elimination (AHE) [6] have been used for modulation control. Since SVM strategy have been widely used for control $\mathrm{AC}$ machine this technique based on the principles of space vectors and need to calculated of sector and angle [7]. On the other hand, this strategy gives $15 \%$ more voltage output compare to the classical PWM strategy [8]. Furthermore, it minimizes the harmonic distortion as well as loss due to minimize number of commutations in the inverter. Nevertheless, this strategy is difficult to implement.

In [9], the author propose a new SVPWM strategy based on calculated the minimum (Min) and maximum (Max) of three-phase voltages. The proposed SVPWM strategy is simple and easy to implement compared to the classical SVM technique. In [10], a three-level SVPWM strategy was proposed based on neural networks controller. Three-level SVPWM and fuzzy logic was combined to control the DFIG-based 
WECSs [11]. A SVPWM strategy was designed to control the four-level inverter [12]. In [13], an indirect vector control (IVC) and fuzzy SVPWM technique were combined to reduces the harmonic distortion of current. In [14], DVC strategy based on two-level fuzzy SVPWM technique to regulate stator reactive and active power of the DFIG. In this paper, a SVPWM strategy of the seven-level inverter is presented. The rotor side converter is controlled based on DVC control to regulate reactive and active powers. The DVC control with seven-level SVM strategy preserves the advantages of the conventional DVC such as fast response, less parameters dependence and reduces the reactive and active powers ripples. In this work, we apply the DVC control on the DFIG using seven-level SVPWM strategy compared to the two-level SVPWM strategy.

\section{MULTILEVEL SPACE VECTOR MODULATION}

The flying capacitor (FC), cascaded H-bridge (CH), neutral-point-clamped (NPC) inverter are the three main different multilevel inverter structures which are used in industrial applications with separate dc sources [15]. The multilevel inverter has drawn large interest in high power industry. They present a latest set of aspects to facilitate and utilized in reactive power compensation. Traditional two-level inverter require six switches and two dc sources separately [16]. The main drawback in traditional two-level is that the harmonic distortion of current and voltage. In order to reduce harmonic distortion of voltage and current, the seven-level NPC inverter is proposed in this paper. A five-level inverter topology is presented in [17]. Multicarrier sinusoidal pulse width modulation based multilevel inverter is presented in [18]. The modulation strategy used in this paper is SVPWM strategy. The major drawback of this modulation strategy is its complex control method to control the multilevel inverter. A new SVM scheme for multilevel invereter presented [9], the proposed SVPWM scheme is simple modulation scheme and easy to implement compared to conventional SVM technique. This proposed technique based on calculating the minimum and maximum of three-phase voltages. The SVPWM strategy of the two-level inverter is shown in Figure 1. This paper presents a new SVPWM modulation scheme of seven-level NPC inverter. Figure 2 shows the SVPWM technique of seven-level NPC inverter. It is observed that the proposed strategy is simple control and easy to implement.

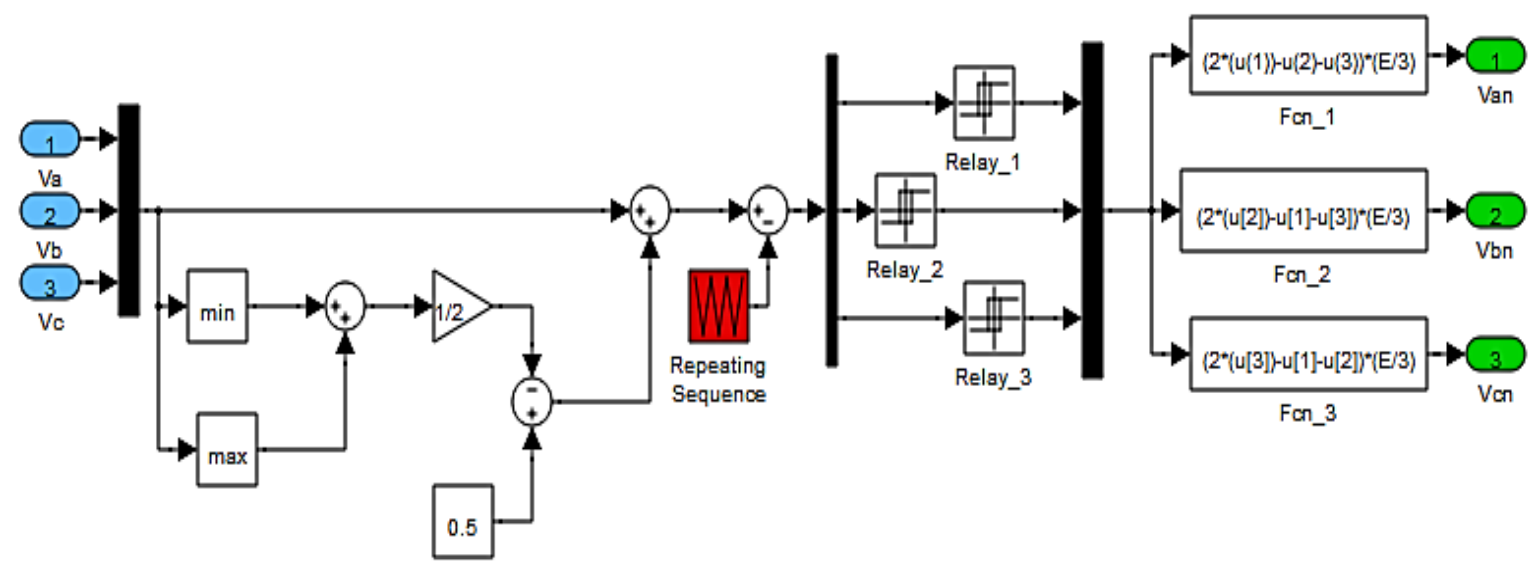

Figure 1. Block diagram of the two-level SVPWM strategy

\section{DVC CONTROL SCHEME}

The DVC control is the simplest and most efficient way to drive and control the DFIG. It simplifies the dynamic of the machine and makes the behavior similar to the one of a direct current (DC) machine. It will allow us to control the reactive and active powers independently. This decoupling is obtained by pointing the $d$ axe of the (d-q) frame on either the stator, rotor or gap fluxes for simplifying constraints, we choose the stator flux aligned to the direct stator flux, then we have [19]:

$$
\psi_{d s}=\psi_{s} \text { and } \psi_{q s}=0
$$




$$
\left\{\begin{array}{l}
V_{d s}=0 \\
V_{q s}=\omega_{s} \psi_{s}
\end{array}\right.
$$

where $d, q$ is the index of the direct and quadrature axes. The stator flux orientation is shown in Figure 3.

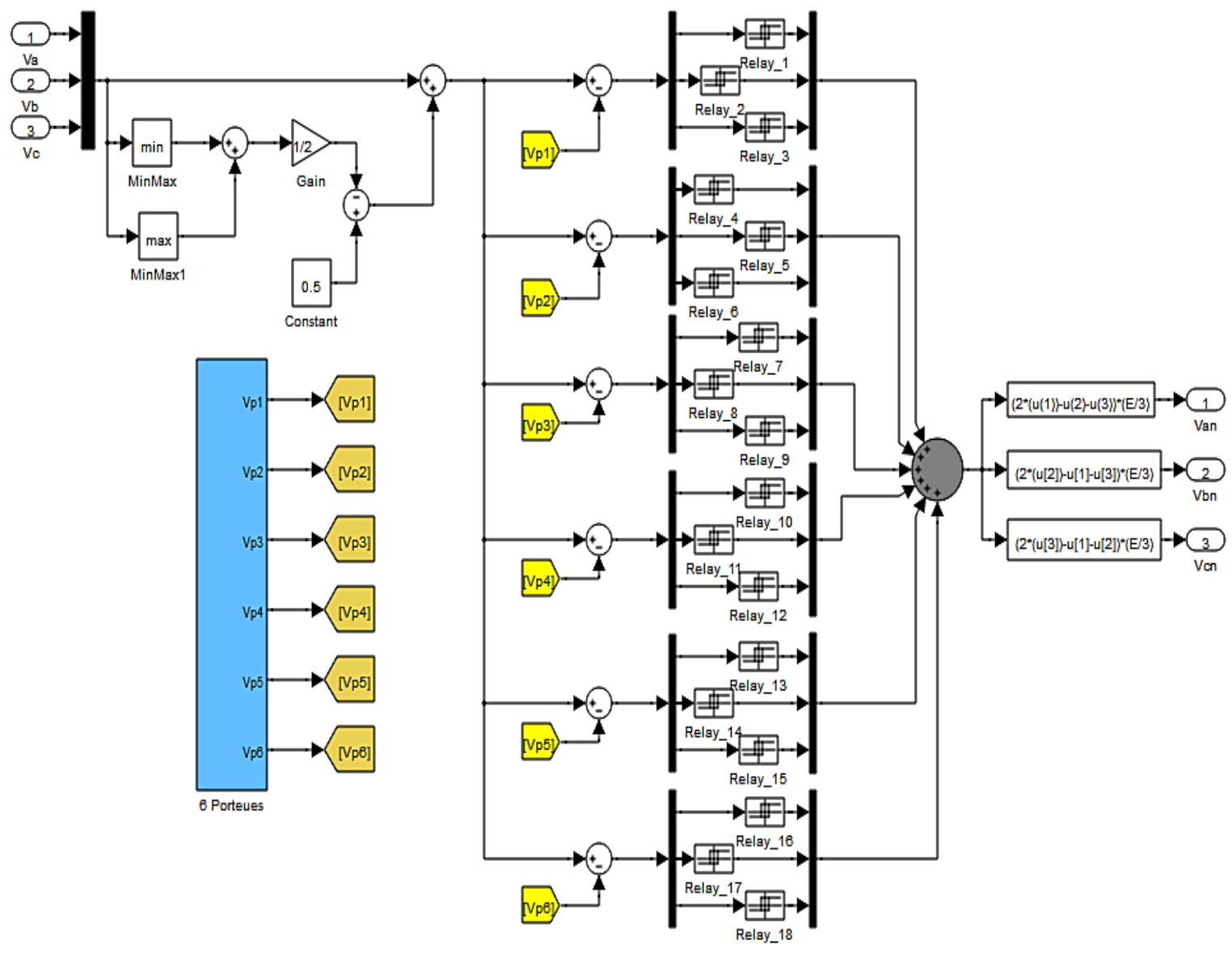

Figure 2. Block diagram of seven-level SVPWM strategy

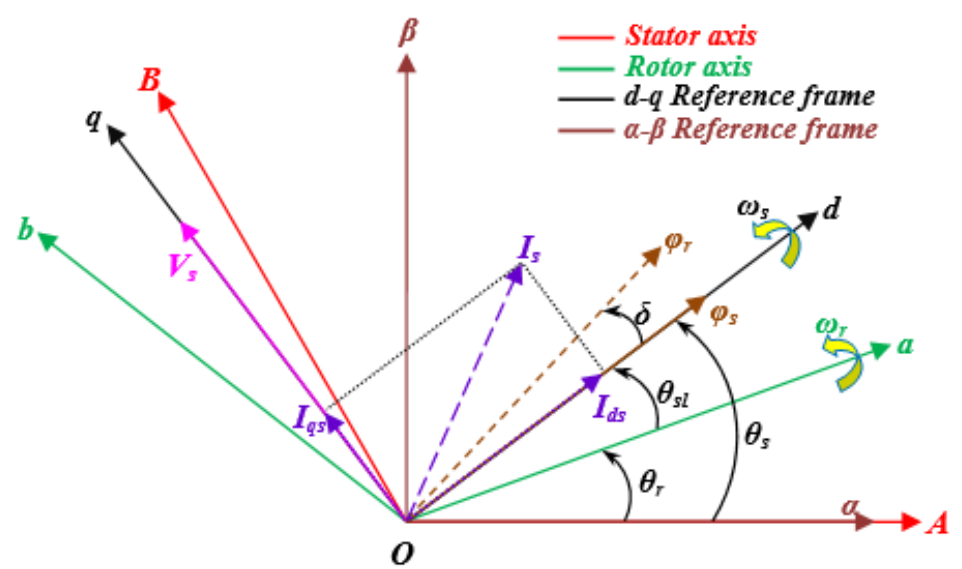

Figure 3. Stator flux orientation 
The expressions of stator current are defined by:

$$
\left\{\begin{array}{l}
I_{d s}=-\frac{M}{L_{s}} I_{d r}+\frac{\psi_{s}}{L_{s}} \\
I_{q s}=-\frac{M}{L_{s}} I_{q r}
\end{array}\right.
$$

and the reactive and active powers can be written as follows:

$$
\left\{\begin{array}{l}
P_{s}=-\frac{3}{2} \frac{\omega_{s} \psi_{s} M}{L_{s}} I_{q r} \\
Q_{s}=-\frac{3}{2}\left(\frac{\omega_{s} \psi_{s} M}{L_{s}} I_{d r}-\frac{\omega_{s} \psi_{s}^{2}}{L_{s}}\right)
\end{array}\right.
$$

The electromagnetic torque can then be expressed by:

$$
C_{e m}=-\frac{3}{2} n_{p} \frac{M}{L_{s}} I_{q r} \psi_{d s}
$$

The rotor voltages can be expressed [20]:

$$
\left\{\begin{array}{l}
V_{d r}=R_{r} \cdot I_{d r}-g \cdot w_{s} \cdot\left(L_{r}-\frac{M^{2}}{L_{s}}\right) \cdot I_{q r} \\
V_{q r}=R_{r} \cdot I_{q r}+g \cdot w_{s} \cdot\left(L_{r}-\frac{M^{2}}{L_{s}}\right) \cdot I_{d r}+g \cdot \frac{M \cdot V_{s}}{L_{s}}
\end{array}\right.
$$

The DVC control with SVM strategy designed to control the DFIG is illustrated in Figure 4.

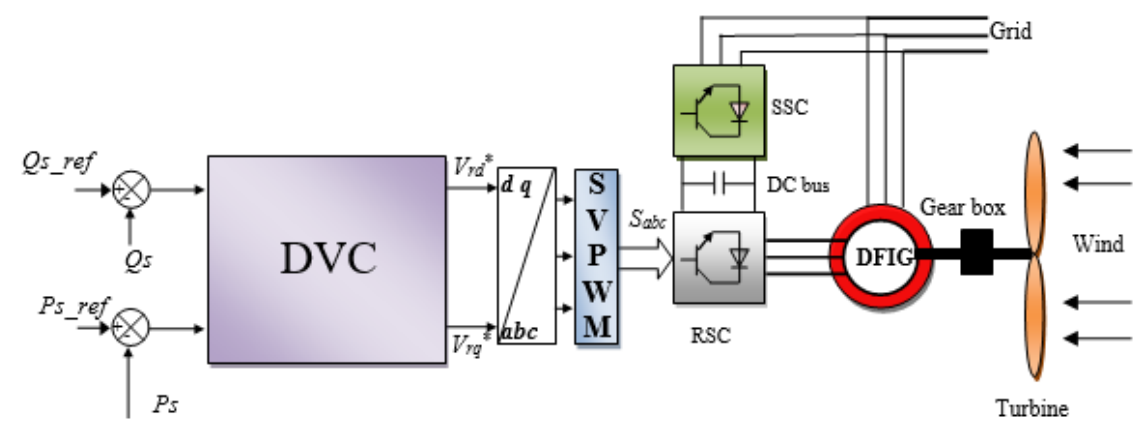

Figure 4. DVC control of a DFIG using SVPWM strategy

\section{SIMULATION RESULTS}

The proposed DVC control with seven-level SVPWM strategy (DVC-7L-SVPWM) for DFIG application is designed and simulated in Matlab/Simulink software. The DFIG used in this work is a 1.5 MW, whose nominal parameters are indicated in the following:

a. Rated values: $1.5 \mathrm{MW}, 380 / 696 \mathrm{~V}, 50 \mathrm{~Hz}$.

b. Rated parameters: $\mathrm{p}=2, \mathrm{Rs}=0.012 \Omega, \mathrm{Rr}=0.021 \Omega, \mathrm{Ls}=0.0137 \mathrm{H}, \mathrm{Lr}=0.0136 \mathrm{H}$ and $\mathrm{Lm}=0.0135 \mathrm{H}$, $\mathrm{J}=1000 \mathrm{~kg} \cdot \mathrm{m} 2$, fr $=0.0024 \mathrm{Nm}$. s/rad.

c. Simulation results of DVC-7L-SVPWM control of the DFIG are compared with DVC control with twolevel SVPWM strategy.

d. The performance analysis is done with THD value, stator reactive power, stator active power and electromagnetic torque. 


\subsection{Reference tracking test (RTT)}

Figures 5-9 show the obtained simulation results. As it's shown in Figures 7-9, for the DVC-7LSVPWM control and DVC-2L-SVPWM control, the active and reactive powers track almost perfectly their references values. Moreover, the DVC-7L-SVPWM control reduced the powers ripples and electromagnetic torque compared to the DVC-2L-SVPWM as shown in Figures 10-12. On the other hand, Figures 5-6 show the total harmonic distortion of stator current of the DFIG for proposed strategies. It can be clearly observed that the total harmonic distortion value is minimized for DVC-7L-SVPWM control (THD $=0.90 \%)$ when compared to DVC-2L-SVPWM control scheme (THD $=1.25 \%$ ).
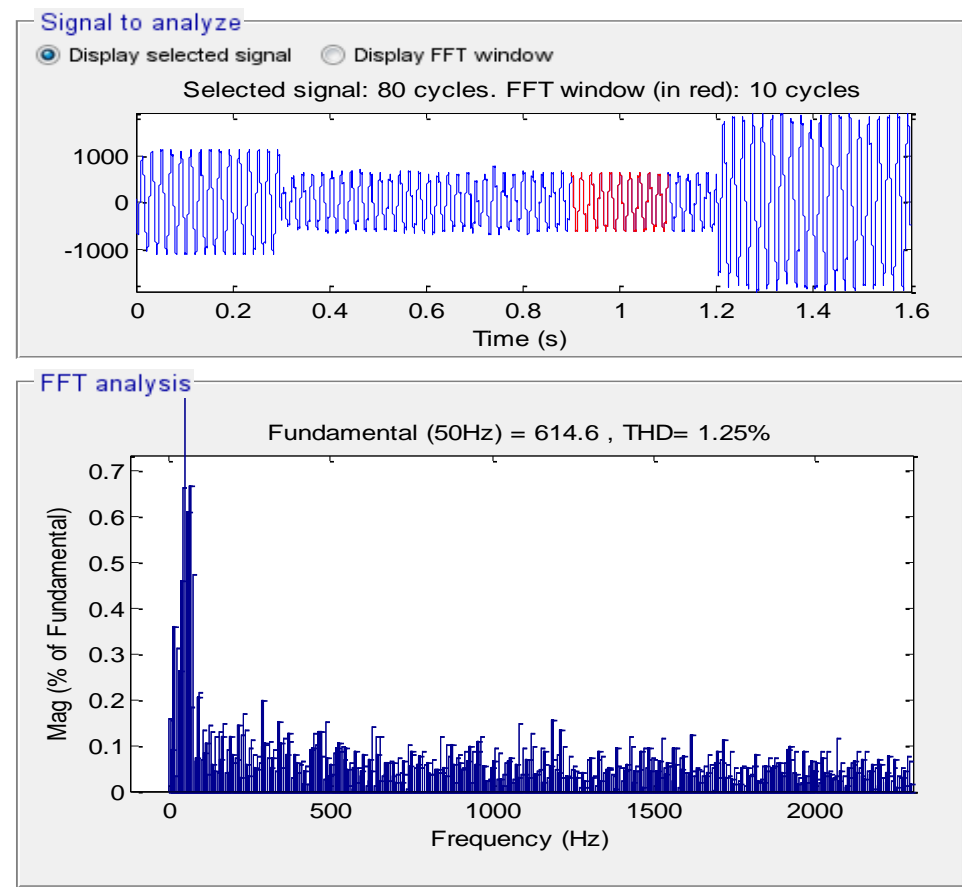

Figure 5. THD of stator current for DVC-2L-SVPWM control
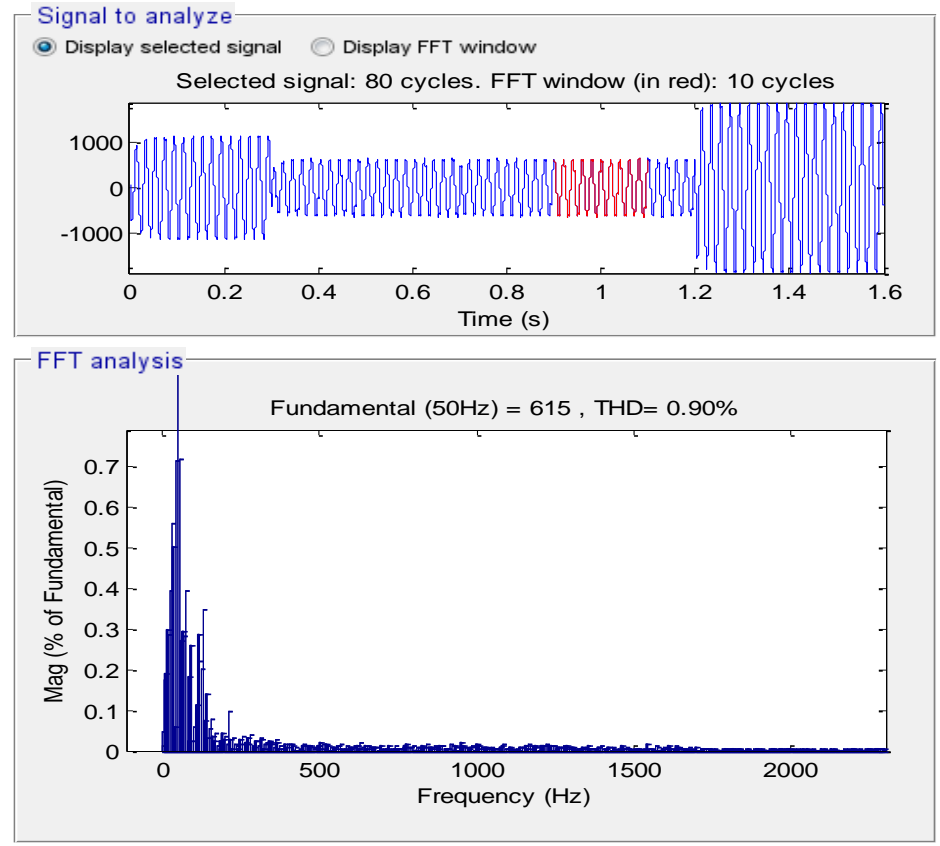

Figure 6. THD of stator current for DVC-7L-SVPWM control 


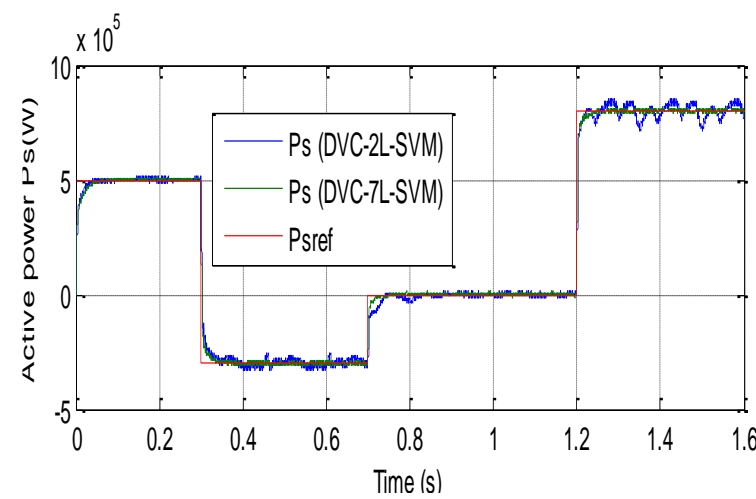

Figure 7. Stator active power

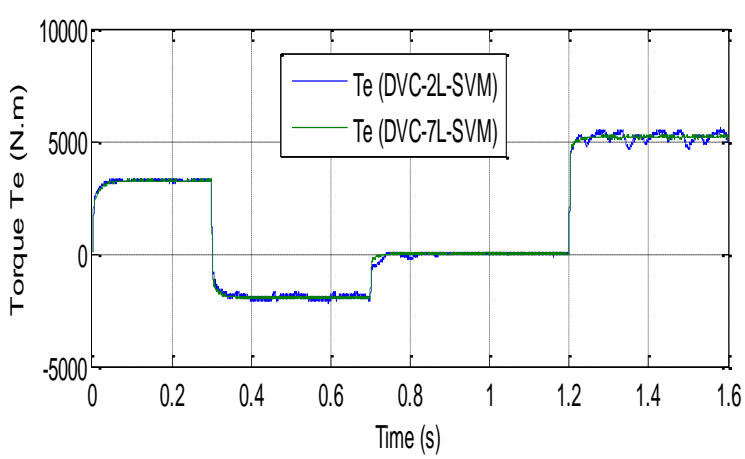

Figure 9. Electromagnetic torque power

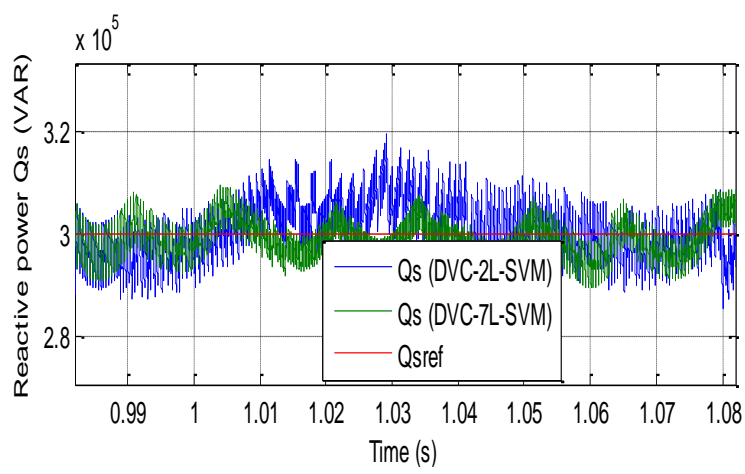

Figure 11. Zoom in the reactive power

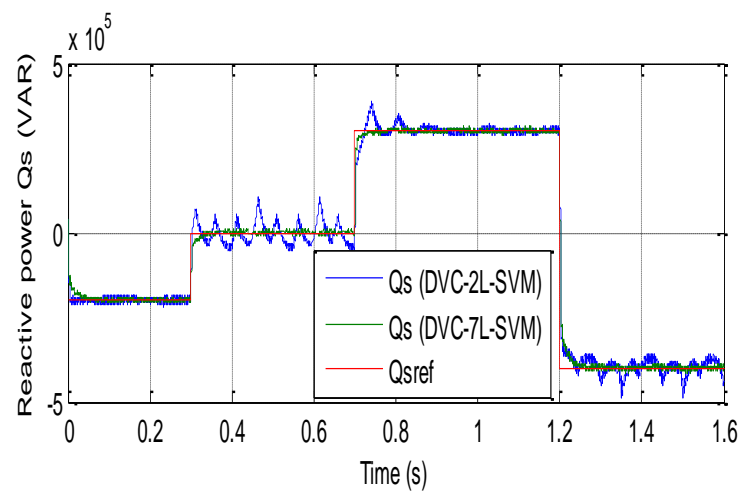

Figure 8. Stator reactive power

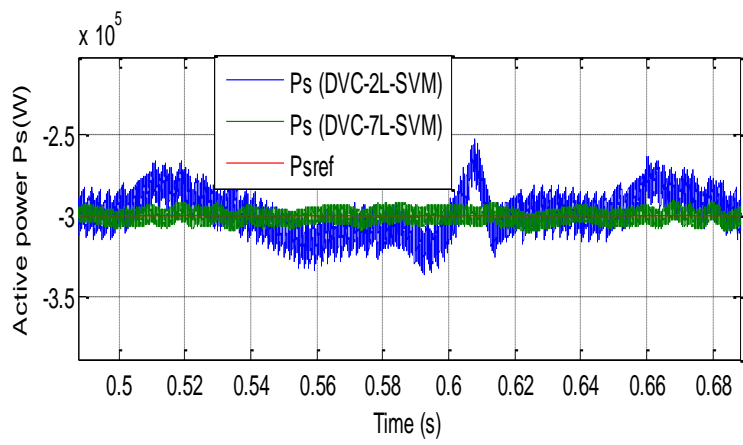

Figure 10. Zoom in the active power

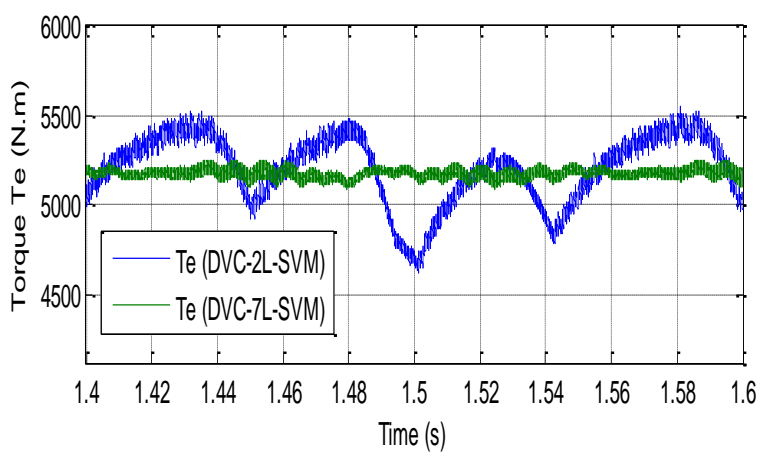

Figure 12. Zoom in the electromagnetic torque

\subsection{Robustness test (RT)}

In this part, the nominal value of the $R_{r}$ and $R_{s}$ is multiplied by 2 , the values of inductances $L_{s}, M$, and $L_{r}$ are multiplied by 0.5 . Simulation results are presented in Figures 13-20. As it's shown by these figures, these variations present an apparent effect on the electromagnetic torque, stator active and stator reactive powers. However, the effect appears more significant for the DVC-7L-SVPWM compared to DVC7L-SVPWM control scheme as shown in Figures 18-20. On the other hand, these results show that the THD value of stator current in the DVC-7L-SVPWM control has been reduced significantly. Table 1 shows the comparative analysis of THD value. Thus, it can be concluded that the DVC-7L-SVPWM control scheme is more robust than the DVC-2L-SVPWM control scheme one. 

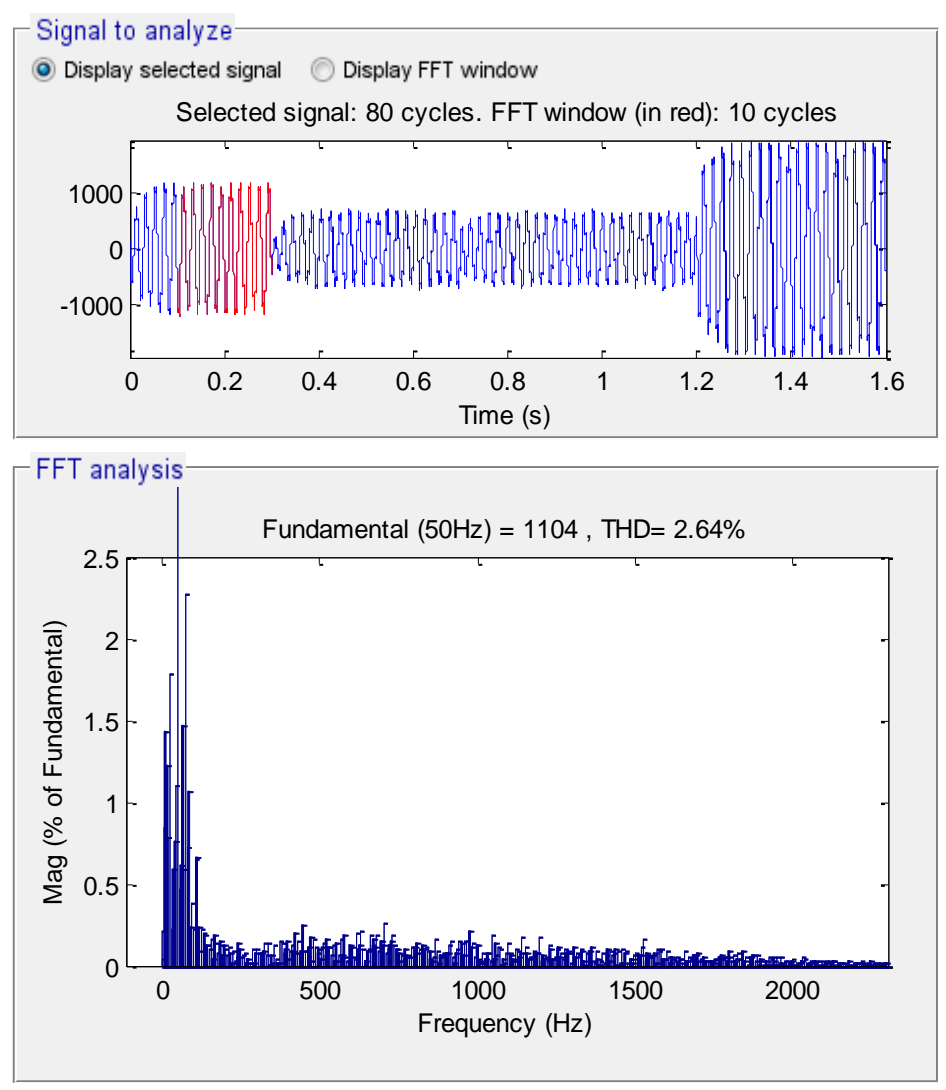

Figure 13. THD of stator current for DVC-2L-SVPWM control
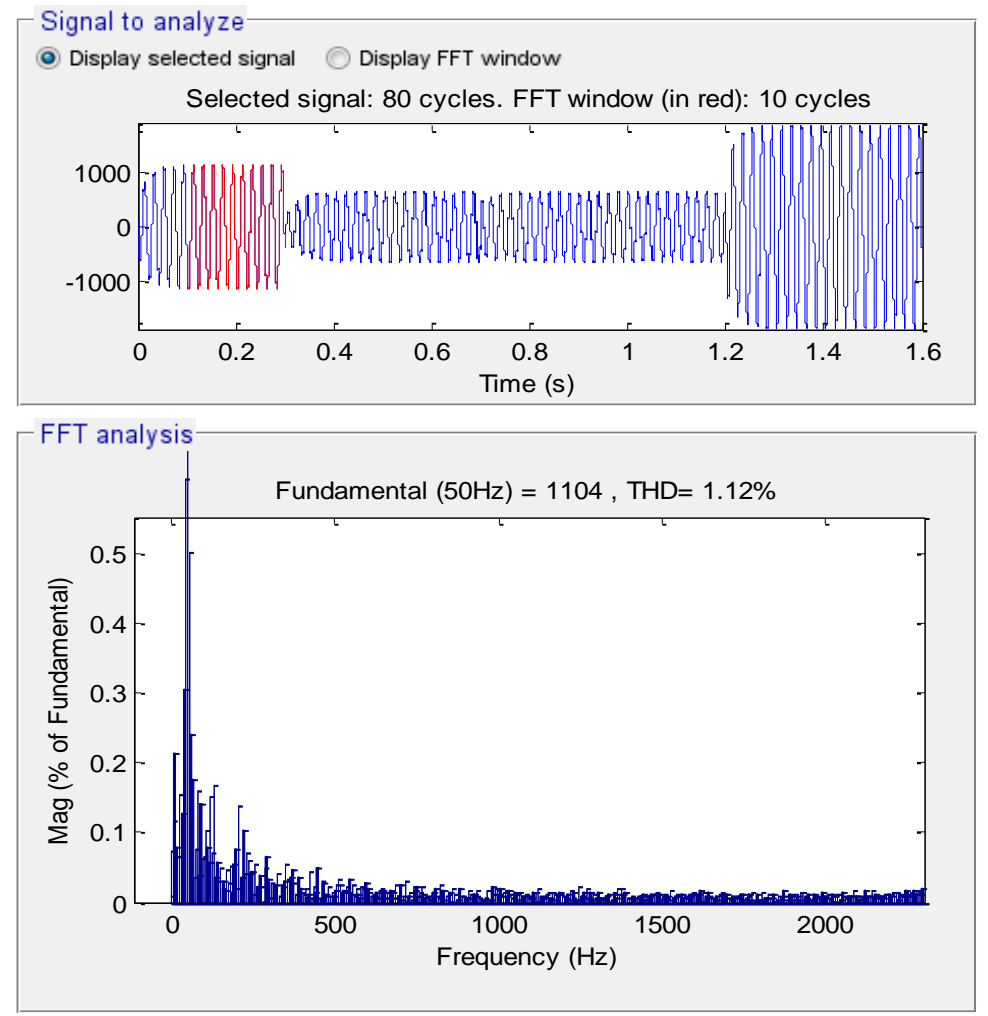

Figure 14. THD of stator current for DVC-7L-SVPWM control 


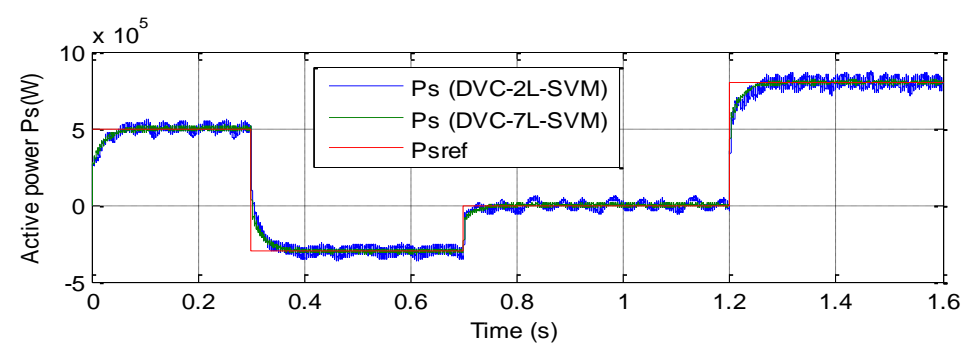

Figure 15. Stator active power

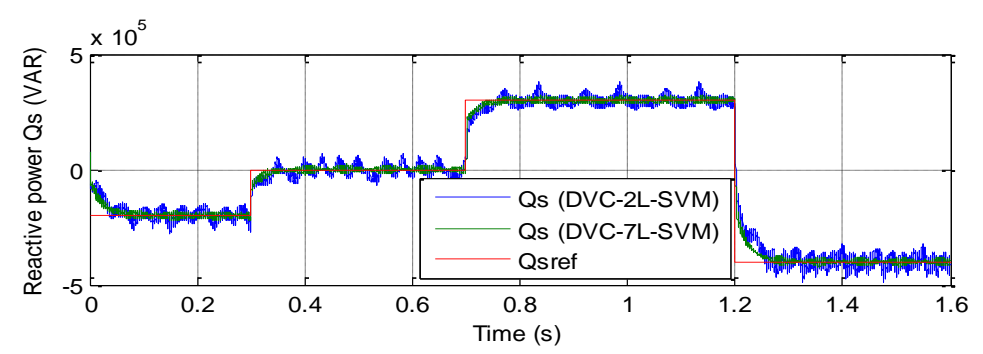

Figure 16. Stator reactive power

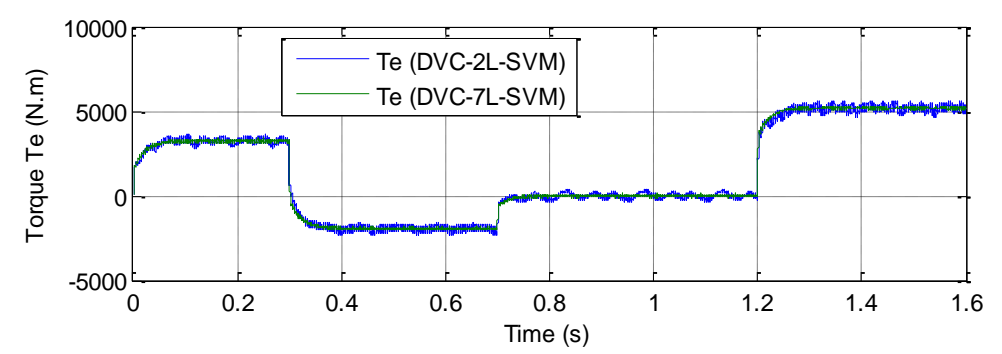

Figure 17. Electromagnetic torque

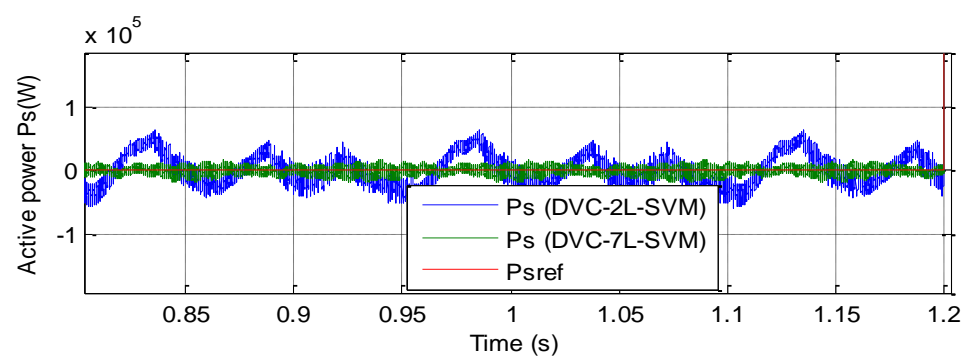

Figure 18. Zoom in the active power

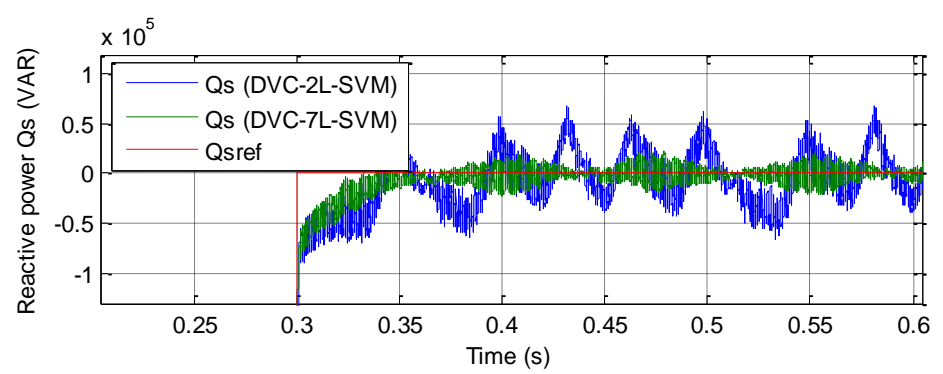

Figure 19. Zoom in the reactive power 


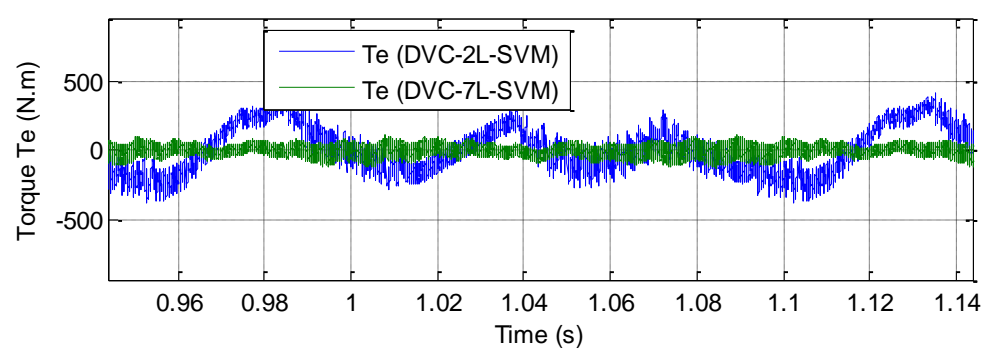

Figure 20. Zoom in the electromagnetic torque

Table 1. Comparative analysis of THD value (RT)

\begin{tabular}{lcc}
\hline & \multicolumn{3}{c}{ THD (\%) } \\
& DVC-2L-SVPWM & DVC-7L-SVPWM \\
\hline Stator current (Ias) & 2.64 & 1.12 \\
\hline
\end{tabular}

\section{CONCLUSION}

This paper presents simulation results of DVC strategy of a DFIG, using the modulation strategy of the seven-level SVPWM and two-level SVPWM technique. With results obtained from simulation, it is clear that for the same operation condition, the DFIG reactive and active control with DVC using seven-level SVPWM had better performance than the two-level SVPWM technique and that is clear in the spectrum of phase stator current harmonics which the use of the seven-level SVPWM strategy, it is reduced of harmonics more than two-level SVPWM strategy.

\section{REFERENCES}

[1] H. Benbouhenni, "Comparative study between different vector control methods applied to DFIG wind turbines," Majlesi Journal of Mechatronic Systems, vol. 6, no. 4, pp. 15-23, 2018.

[2] Z. Boudjema, A. Meroufel, A. Amari, "Robust control of a doubly fed induction generator (DFIG) fed by a direct AC-AC converter," Przegląd Elektrotechniczny, vol. 88, no. 12, pp. 213-221, 2012.

[3] P. L. Kamani and M. A. Mulla, "Middle-Level SHE Pulse-Amplitude Modulation for Cascaded Multilevel Inverters," IEEE Transactions on Industrial Electronics, vol. 65, no. 3, pp. 2828-2833, 2018.

[4] S. K. Sahoo and T. Bhattacharya, "Phase-Shifted Carrier-Based Synchronized Sinusoidal PWM Techniques for a Cascaded H-Bridge Multilevel Inverter," IEEE Transactions on Power Electronics, vol. 33, no. 1, pp. 513-524, 2018.

[5] B. Kirankumar, Y. V. Siva Reddy and M. Vijayakumar, "Multilevel inverter with space vector modulation: intelligence direct torque control of induction motor," IET Power Electronics, vol. 10, no. 10, pp. 1129-1137, 2017.

[6] Z. Du, L. M. Tolbert and J. N. Chiasson, "Active harmonic elimination for multilevel converters," IEEE Transactions on Power Electronics, vol. 21, no. 2, pp. 459-469, 2006.

[7] H. Obdan, M. C. Ozkilic, "Performance Comparison of 2-level and 3-level converters in a wind energy conversion system," Rev. Roum. Sci. Techn. -Electrotechn. Et Energ, vol. 61, no. 4, pp. 388-393, 2016.

[8] Y. Bekakra, D. Ben Attous, "Comparison study between SVM and PWM inverter in sliding mode control of active and reactive power control of a DFIG for variable speed wind energy," International Journal of Renewable Energy Research, vol. 2, no. 3, pp. 471-476, 2012.

[9] H. Benbouhenni, "Comparative study between NSVM and FSVM strategy for a DFIG-based wind turbine system controlled by neuro-second order sliding mode," Majlesi Journal of Mechatronic Systems, vol. 7, no. 1, pp. 33-43, 2018.

[10] H. Benbouhenni, Z. Boudjema, A. Belaidi, "DFIG-based wind turbine system using three-level neural space vector modulation technique," Majlesi Journal of Mechatronic Systems, vol. 7, no. 2, pp. 37-48, 2018.

[11] H. Benbouhenni, Z. Boudjema, A. Belaidi, "Using three-level Fuzzy space vector modulation method to improve indirect vector control strategy of a DFIG based wind energy conversion systems," International Journal of Smart Grid, vol.2, no.3, pp.155-171, 2018.

[12] H. Benbouhenni, Z. Boudjema, A. Belaidi, "DFIG-based wind turbine system using four-level FSVM strategy," Majlesi Journal of Energy Management, vol. 6, no. 3, pp. 7-19, 2017.

[13] H. Benbouhenni, Z. Boudjema, A. Belaidi, "Indirect vector control of a DFIG supplied by a two-level FSVM inverter for wind turbine system," Majlesi Journal of Electrical Engineering, vol. 13, no. 1, pp. 45-54, 2019.

[14] H. Benbouhenni, Z. Boudjema, A. Belaidi, "Direct vector control of a DFIG supplied by an intelligent SVM inverter for wind turbine system," Iranian Journal of Electrical and Electronic Engineering, vol. 15, no. 1, pp-45$55,2019$. 
[15] T. Venkatraman, S. Periasany, "Multilevel inverter topology with modified pulse width modulation and reduced switch count," Acta Polytechnica Hungarica, vol. 15, no. 2, pp. 141-167, 2018.

[16] A. Thiruvengadam, K. Vdhayakumar, "An enhanced H-bridge multilevel inverter with reduced THD, conduction, and switching losses using sinusoidal tracking algorithm," Energies, vol. 12, no. 81, pp. 2-22, 2019.

[17] C. I. Odeh and D. B. N. Nnadi, "Single-phase 9-level hybridised cascaded multilevel inverter," IET Power Electronics, vol. 6, no. 3, pp. 468-477, 2013.

[18] K. K. Gupta, S. Jain, "Topology for multilevel inverters to attain maximum number of levels from given DC sources," IET Power Electronics, vol. 5, no. 4, pp. 435-446, 2012.

[19] M. Adjoudj, M. Abid, A. Aissaoui, Y. Ramdani, H. Bounoua, "Sliding mode control of a doubly fed induction generator for wind turbines,” Rev. Roum. Sci. Techn. -Electrotechn. Et Energ, vol. 56, no. 1, pp. 15-24, 2011.

[20] A. Medjber, A. Moualdia, A. Mellit, M. A. Guessoum, "Comparative Study Between Direct and Indirect Vector Control Applied to A Wind Turbine Equipped with a Double-Fed Asynchronous Machine Article," International Journal of Renewable Energy Research, vol. 3, no. 1, pp. 88-93, 2013.

\section{BIOGRAPHY OF AUTHOR}

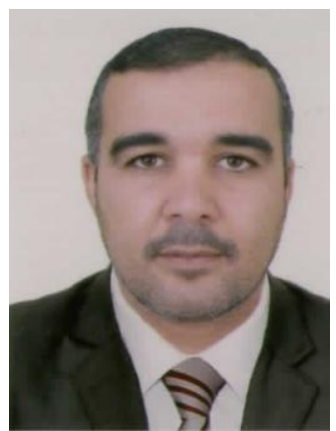

H. Benbouhenni was born in chlef, Algeria. $\mathrm{He}$ is a $\mathrm{PhD}$ student in the Departement of Electrical Engineering, National Polytechnique School of Oran Maurice Audin, Algeria. He received a M.A. degree in automatic and informatique industrial in 2017. His research activities include the application of robust control in the wind turbine power systems. 